\section{THE SYCAMORE TREE}

\section{BY ALEXANDER L. HOWARD}

$\mathrm{I}^{\mathrm{N}}$ company with many other prosperous exotics, the so-called 'sycamore' has lived for many. generations in Great Britain under a false name. Sycamore is an attractive name, but as applied to this tree it is both incorrect and misleading: the term Acer pseudoplatanus is equally so. The word 'sycamore', spelt by the early botanists 'sycomore', is the name for a fig tree, very well described by Pliny, 69-115 A.D. The botanical term Acer pseudoplatanus is inaccurate, as in no respect can the sycamore be considered a spurious or, in modern phraseology, ersatz treə. The only excuse which can be put forward. is that the leaf resembles the plane in its shade of green, and also in its shape. If this reason be sufficient, then most certainly the botanical name for the wych elm should be Ulmus pseudo-corylus, since the resemblance between the leaf of the wych elm and that of the hazel (Corylus avellana) is greater. Four authorities of very different dates all bear witness to this long-standing mistake.

Pliny says :

"In Aegypt likewise there be found many trees which grow not elsewhere : and principally the Sycomore, which thereupon is called the Aegyptian Figtree. The tree for leafe, bignesse, and barke, is like unto the Mulberie tree. It beareth fruit not upon the branches, but out of the very body of the stocke. And the same is a passing sweet fig, but without any graines at all within. It doth increase in exceeding great abundance."

John Evelyn (1664) :

"The Sycamore or Wild Figtree falsely so-called, is our Acer Magus or Broad-leaved Mas, one of the Maples."

Students of the New Testament remain under the impression that the tree into which Zaccheus climbed to see Christ pass on his way to Jerusalem was the sycamore as we know it, whereas it was in fact the Ficus Sycamorus - the fig mulberry. Even Jacob S. Strutt in his "Sylva Britannica" falls into this error.

William Boutcher, nurseryman, in 1776, writes :

"The greater Maple, in England falsely called the Sycamore and in Scotland the Plane tree."

Whether the term 'broad-leaved maple' as in America, the botanical name Acer macrophyllum, or A. Magus, or any other scientific name should be applied, matters not, but the tree should certainly not be called sycamore or Acer pseudoplatanus. In bark, twig, leaf, fruit, and flower, and more particularly in wood, there is no kind of resemblance between the so-called sycamore (English) and the plane. Both trees produce valuable and useful wood, but they are not suitable for similar purposes. Whereas the sycamore is not indigenous to Great Britain, its close relative-the small-leaved or oldEnglish maple-belongs here, as will be seen later. Although the introduction of the sycamore to southern Europe may have occurred at an early date, Pliny does not mention it. The earliest known record is about the fourteenth century, when, according to the Rev. C. A. Johns, Chaucer speaks of it as "a rare exotic".

Elwes quotes :

"Clement Reid hazards the suggestion that it was introduced by the Romans. Ray states, Synopsis 230, published in 1690, that the Sycamore was then planted in cemeteries and about the houses of the nobility, and that it was nowhere wild in England."
All records show that it did not receive a very warm welcome. To quote John Evelyn again :

"the Sycamore is much more in reputation for its shade than it deserves ... for the honey-dew leaves, which fell early like those of the Ash turn to mucilage and noxious insects and putrify with the first moisture of the season, so as they contaminate and marr our walkes, and are therefore by my consent, to be banished from all curious gardens and avenues."

The Rev. C. A. Johns, and all other early writers, speak of it unkindly, but the sycamore, in spite of this unpopular reception, seems to have become well adapted to its new habitat, and full of life, vigour, and determined perseverance, and has now become established in Great Britain.

In youth it cannot be classed among the beautiful trees of our landscape, but in later age the case is different, and the fully matured sycamore is a noble tree holding its own among its neighbours. While it is certainly surpassed in beauty by its cousin, the small-leaved English maple (Acer campestre), it is now an outstanding feature of parks and public gardens, churchyards and stately mansions, where it attains a certain grandeur. The crown in the early spring is clothed with rich green leaves falling in graceful sprays, which later turn to a darker colour, reminiscent of the ebony in tropical regions. As autumn approaches, the small-leaved maple turns to a rich gold, while the sycamore still holds its sombre green, only broken by the appearance of black spot, against which precaution should be taken. While its life may be extended far beyond 150 years, it cannot be said to compare in this respect with our indigenous trees, and the forester should therefore realize that it should be harvested at an earlier age than othersperhaps not later than 80-100 years, after which time the quality of the tree deteriorates. "English Forests and Forest Trees", published in 1853, mentions as the largest known sycamore at that time the tree at Bishopston in Renfrewshire :

"which measured 60 feet in height and 20 feet in girth. This tree is known to have been planted before the Reformation, and is supposed to be not less than 300 years old, yet it has the appearance of being perfectly sound."

But Elwes in 1913 says :

"I think the palm must be awarded to a tree near the Marquess of Ripon's house at Studley Royal, Yorkshire. This tree is about 104 feet high, by $17 \frac{1}{2}$ feet in girth. It has a very large burr close to the ground, where it is $29 \frac{1}{2}$ feet round, and a clear bole of about 30 feet."

$\mathrm{He}$ also mentions another tree at Powerscourt, Co. Wicklow, which "is a fine wide-spreading tree 80 feet high by 14 feet in girth". When I saw this tree in 1936 it was an outstanding example of grace and beauty, and always attracted the attention of many who travelled far to see it.

When felled at its prime, the sycamore tree provides a wood of such exceptional value that for this purpose alone its continued prosperity should be assured. The colour of the wood is creamy white, and the grain close, compact, and capable of an ivory surface-whether straight-grained and plain or beautifully figured with mottle or broken roe and mottle, it is always attractive and comparable to the wood of the same tree which has been imported from Canada and America in considerable quantities. The timber from these sources can be mixed with our own home-grown products, so that they are indistinguishable. When the wood is stained with a 
solution it is possible to produce a surface which is so universally admired that it has proved invaluable for decorative purposes such as panelling and interior decoration of houses, and furniture : this production is known as 'hare-wood'. Sycamore has been used for the making of a great number of domestic utensils and furniture in its unstained condition, and for many years has been greatly in demand for rollers for printing linen. In this connexion Elwes mistakenly assumes that the outstanding value of this wood is for these rollers. In actual fact, the great value of sycamore renders it far too costly for this purpose, as the strict selection for quality and waste in conversion, both essential for this work, can only result in a loss.

While its natural colour is not always improved by exposure to light and air, if it is used where continual scouring and cleaning is necessary, it is an admirable medium, and since the eighteenth century it has been much in demand for kitchen tables, counters and the like. The gangway for the admission of Royal personages to King Edward's steam yacht was, by his special command, constructed of sycamore, which by continual scrubbing kept its spotless white appearance.

The small-leaved English maple (Acer campestre), improperly called the 'common or field maple', deserves especial attention. Why the undignified term 'common' should have been applied to it is difficult to understand. The dictionary gives as the definition of 'common', "vulgar, mean, usual, and public", but the tree is none of these-there is nothing mean about it, and it is by no means com. mon; in fact, to-day, whatever it may have been in the past, it is uncommon. It is one of the most beautiful trees which ornament the country, principally in parks and surrounding stately mansions. Throughout its life, whether in spring, summer, autumn or winter, it is a graceful feature of the landscape. Unadorned, its branches make a lovely pattern against the winter sky. In spring its tender pale green leaves present a pretty sight. In summer the spread of the foliage is different from all other forest trees; but its full glory is reached in the autumn when the leaves turn to ripe gold.

In the historical place at Cassiobury Park, Watford, the seat of the Earls of Essex, among a unique collection of oaks, chestnuts, beeches, elms and ash trees, there were two early English maples, equal in beauty to any of that noble company, and one of them, probably the best of its kind, was to be found thirty years ago. Its important uses do not seem to have been ever fully recognized. Its suitability for hedgerows has been almost entirely ignored : in suoh places quickthorn, privet, cypress, yew, ivy, beech, hornbeam and Japanese Lonicera nitida are commonly employed, whereas the maple has had to struggle on alone without encouragement. English arboriculturists do not seem to have appreciated either its beauty or its value for timber, which was not the case with those earlier enthusiasts whose writings have come down to posterity. The Rev. C. A. Johns quotes that "Virgil represents one of his kings as seated on a Maple throne", and Pliny says "the trunk for beauty and firmness of grain is inferior only to the Citron wood". It is curious to notice that from the time of Evelyn no one seems to have been interested in furthering the claims of this beautiful tree. The timber generally is little known to-day, although it possesses qualities which would have rendered it invaluable in place of wood which has been imported from other countries. In this category may be named American, Canadian, European, Swedish and Norwegian supplies-most of them unknown to the craftsmen of those earlier times, who depended upon their own home-grown timbers for the supply of domestic utensils made of wood. Indeed, the origin of the name 'mazer' for bowls and drinking cups signified the name of the wood from which they were made, the word 'mazer' being a corruption of the old Welsh word 'masarn'-the maple tree. Such bowls and drinking cups were in common and continual use, and were handed down from father to son as heirlooms.

Even ordinary observers will have noticed the habit which many trees exhibit of throwing out all round the trunk, sometimes at the base, sometimes at the crown, and sometimes in between, the growth of tiny branches massed together. This habit is most pronounced in the English or common maple, and is even more abundantly found in similar trees of other countries. Such examples are highly prized and eagerly sought for, and when cut on the rotary machine, round the tree in veneer, the wood yields a product named 'birds-eye' maple. This peculiar growth increases the value threefold and sometimes more.

The ivory-white colour and the quality of the grain of the small-leaved maple enable the craftsman to produce an article which will withstand continual washing and preserve an ornamental surface. While the grain is tough, it is not brittle, and the tool of the sculptor or engraver can work it with satisfactory results in every direction of its growth. As Pliny says, "it is in great request for many exquisite and sumptuous workes".

In the list of trees which the future forester should establish, planting them again and again, the socalled 'sycamore' and the 'common' English smallleaved maple should certainly receive a prominent place. The man who plants these trees will be repaid in full measure, and in a shorter period of time than in the case of most hardwood trees.

\section{BUILDING RESEARCH IN THE UNITED STATES}

$T$ HE report of the British Building Mission, appointed by the Minister of Works in July 1943, on building methods in the United States, which has now been published by the Ministry of Works (H.M. Stationery Office, 4d. net) contains, among much that is of general interest, a good deal of special interest to scientific workers. This is particularly true of the first part of the report, dealing with the design of buildings. The report points out that American designers, knowing that many buildings of no great age are threatened with obsolescence of equipment and general design, show a tendency to assume that, in view of the rapidity of scientific development and social change, future generations of Americans will demand to live and work in buildings. evolved by themselves and appropriate to their own times; they appear to believe that many of the buildings of the present should be designed strictly for their immediate purpose, and that a limited life for a building may be an advantage rather than the reverse. American manufacturers are accordingly seeking to produce new materials fulfilling the general requirements of serviceable building but costing less 